SOCIOLOGY

\title{
FOCUS ON GLOBAL HEALTH DIPLOMACY
}

\author{
Huang Kunpeng, \\ Belarusian State University, Minsk
}

DOI: https://doi.org/10.31435/rsglobal_conf/25052021/7567

Abstract. The emergence of COVID-19 has ushered in a new phase in China's engagement in global public health diplomacy. This article summarizes the definition of global health diplomacy, as well as some suggestions for China's health diplomacy.

Keywords: global public health diplomacy; definition.

The COVID-19 made the people once again interested in global health diplomacy. The concept of "medical diplomacy" was proposed by Peter Bourne (Peter Bourne) in 1978. He believes that "The United States has not yet fully explored the role of health and medicine as a means of improving international relations. Certain humanitarian issues, especially health issues, can be the basis for establishing dialogue and overcoming diplomatic barriers as they transcend traditional and more. Stormy and alarming fears" [1, p.23-114]. This concept has been developed and matured in recent decades, and thanks to pioneering work in this area, policy-makers and researchers are now familiar with the term "global health diplomacy" [2, p.23-315]. In addition, government officials and international organizations increasingly welcome global health diplomacy as a tool to simultaneously implement plans and improve health and international relations [3, p.161-244]. Chinese scholar Jin Jiyong interprets the attributes of public products and argues that "public health diplomacy refers to the global governance action taken by various actors to address public health security issues [9, p.82-83].

Although the term global health diplomacy has become widespread, it has many different meanings. They are usually divided into three different types of interactions related to international public health problems: (1) mainstream diplomacy, formal negotiations between countries and countries. (2) multilateral diplomacy between countries and other participants or between countries. (3) Informal diplomacy between international public health actors and international partners, including host country officials, nongovernmental organizations, private sector companies and the public interactive.

The term "focused diplomacy" can have many meanings and is defined as interaction between governments, including policy implementation, policy advocacy, negotiation, intelligence and problem diplomacy [4]. For the avoidance of conflict, we limit here the term Classical Westphalian Interpretation: negotiations between countries and between countries to resolve disputes and conclude formal agreements.

Bilateral negotiations between the two countries are the most traditional form of focus diplomacy. It involves high-level negotiations between government officials, who can be health officials or other technical experts, and the result can be a signed agreement that forces the parties to commit themselves.

Based on the historical definitions and concepts of Henry Morgenthau and Henry Kissinger, the classification of mainstream diplomacy includes international negotiations that are supported by multilateral institutions such as the World Health Organization (WHO) and other international organizations that shape agreements and norms. Kickbusch and her Colleagues describe it as "a multilevel multi-stakeholder negotiation process that shapes and manages global health policy"[5, p.32-230]. Today in the world there are about fifty main multilateral agreements in the field of health [6]. The Forum's most interesting global health negotiation is the World Health Assembly (WHA) (WHA), which is the highest decision-making body of the World Health Organization (WHO) and is composed of representatives from all 193 Member States. While the number of formal health agreements negotiated in multilateral negotiations by the World Health Assembly is small, they are significant, including the World Health Organization Framework Convention on Tobacco Control (FCTC) and the revised International Health Regulations that were adopted in 2005 (IHR 2005) (IHR 2005) [7, p. 83-229].

The Framework Convention on Tobacco Control, adopted in 2003, represents years of efforts by public health experts, international lawyers and diplomats to assess evidence, harmonize texts, negotiate treaties and facilitate signature and ratification by various countries. Negotiations require a 
lot of technical expertise to formulate the first evidence-based treaty under the auspices of the World Health Assembly (a milestone in global health) and diplomat to facilitate the treaty process.

In a second example, members of the World Health Assembly in 2005 agreed to comprehensively reform the international legal framework for surveillance, reporting and response. The International Health Regulations 2005 oblige all WHO Member States to develop and maintain basic capabilities to detect, assess, report and respond to public health incidents, and to promptly notify the World Health Organization (WHO) of public emergencies. health care that may affect other countries.

Negotiations between the Convention and the International Health Regulations 2005 focused not only on "high diplomacy" of national sovereignty (the language of principles, standards and obligations), but also on epidemiological evidence and data-driven decision-making. Both agreements impose obligations on contracting states that are legally binding to achieve public health goals.

In the context of negotiations on trade in aid, and even in forums such as the Convention on Biological Diversity, other organizations of the United Nations system directly or indirectly influence negotiations on healthy practices. For example, the Agreement on Trade-Related Aspects of Intellectual Property Rights (TRIPS) (TRIPS), adopted by the World Trade Organization (WTO) (WTO) in 1995, proves that agreements that are not directly related to health will affect the diplomatic environment and politics. health care. The TRIPS Agreement introduced minimum standards for the protection and enforcement of intellectual property rights for WTO members and extended international standards for patent protection. However, many developing country leaders and advocacy groups believe that TRIPS can deprive the hardest-hit countries of the ability to afford HIV / AIDS treatment. Finally, in 2001, ministerial negotiations issued a statement confirming that TRIPS allows states to issue compulsory licenses in the face of a public health crisis. Neither the agreement nor subsequent agreements bridge the gap between high-income countries, where most of the major drug manufacturers are located, and emerging economies seeking to maintain flexibility in local drug production and export under certain conditions. Instead, the heated debate spread to other discussions about trade and health [8, p.58-317].

Over the past two decades, the understanding of public health risks applicable to global governance has expanded from existential threats such as epidemics or emerging infectious diseases to the fundamental determinants of chronic diseases such as tobacco use. The drive for international intervention to reduce mortality from infectious and noncommunicable diseases has created new pressures on multilevel governance and key diplomacy to achieve health goals through an international legal framework. This work requires the acquisition of medical knowledge through diplomatic and legal activities in international negotiations, including in areas that are not directly related to global health.

In the time of COVID-19, China had tried himself to cooperate with WHO and controled the COVID-19 fastly, and China also is preparing to help other countries who are in fluted by COVID-19 now, I think that reviewing and analyzing the definition of global health diplomacy will help China better manage global health governance.

\section{REFERENCES}

1. Bourne P. A Partnership for International Health Care /P. Bourne// Public Health Reports. - 1978. № 93(2) -P.23-114.

2. Adams V, Novotny T, Leslie H. Global Health Diplomacy / V. Adams, T. Novotny, H. Leslie// Medical Anthropology. -2008.- № 27(4) - P.23-315.

3. Drager N, Fidler D. Foreign Policy, Trade and Health: At the Cutting Edge of Global Health Diplomacy/ N. Drager, D. Fidler// Bulletin of the World Health Organization. - 2007. - № 85(3) - P.161-244.

4. Adams $G$, Bacchus WI. Foreign Affairs Budget for the Future: Fixing the Crisis in Diplomatic Readiness/ G. Adams, WI. Bacchus // Washington, DC: American Academy of Diplomacy and Stimson Center - 2008.

5. Kickbusch I, Silberschmidt G, Buss P. Global Health Diplomacy: The Need for New Perspectives, Strategic Approaches and Skills in Global Health/ I. Kickbush, G. Silberschmidt, P. Buss// Bulletin of the World Health Organization. - 2007. - № 85(3) - P.32-230.

6. Kates J, Wexler A, Lief E, Seegobin V.Donor Funding for Health in Low- \& Middle-Income Countries, 20012008 / J. Kates, A. Wexler, E. Lief, V. Seegobin// Washington, DC: Kaiser Family Foundation. - 2010.

7. Gostin LO. Public Health Law: Power, Duty, Restraint/LO.Gostin// 2nd ed. Berkeley: New York: University of California Press. - 2008. - P. 83-229.

8. Abbott F. The WTO Medicines Decision: World Pharmaceutical Trade and the Protection of Public Health /F. Abbott// American Journal of International Law. - 2005.-№ 99(317). - P.58-317.

9. Jin Jiyong. On Public Health Diplomacy. /Jiyong Jin/ Diplomatic Review-2008. - № 104.-P. 82-83. 